\title{
Anatomical Study of the Branch of the Palmaris Longus Muscle for its Transfer to the Posterior Interosseous Nerve
}

\author{
Estudio Anatómico del Ramo del Músculo Palmar Largo \\ para su Transferencia al Nervio Interóseo Posterior
}

\author{
Edie Benedito Caetano ${ }^{1}$; Luiz Angelo Vieira ${ }^{1}$; Maurício Benedito Ferreira Caetano²; \\ Cristina Schmitt Cavalheiro ${ }^{3}$; Marcel Henrique Arcuri ${ }^{3}$ \& Luís Cláudio Nascimento da Silva Júnior ${ }^{3}$
}

CAETANO, E. B.; VIEIRA, L. A.; FERREIRA, C. M. B.; CAVALHEIRO, C. S.; ARCURI, M. H. \& SILVA JÚNIOR, L. C. N. Anatomical study of the branch of the palmaris longus muscle for its transfer to the posterior interosseous nerve. Int. J. Morphol., 37(2):626-631, 2019.

SUMMARY: The objective of the study was to evaluate the anatomical characteristics and variations of the palmaris longus nerve branch and define the feasibility of transferring this branch to the posterior interosseous nerve without tension. Thirty arms from 15 adult male cadavers were dissected after preparation with $20 \%$ glycerin and formaldehyde intra-arterial injection. The palmaris longus muscle (PL) received exclusive innervation of the median nerve in all limbs. In most it was the second muscle of the forearm to be innervated by the median nerve. In 5 limbs the PL muscle was absent. In 5 limbs we identified a branch without sharing branches with other muscles. In 4 limbs it shared origin with the pronator teres (PT), in 8 with the flexor carpi radialis (FCR), in 2 with flexor digitorum superficialis (FDS), in 4 shared branches for the PT and FCR and in two with PT, FCR, FDS. The mean length was (4.0 \pm 1.2$)$ and the thickness $(1.4 \pm 0.6)$. We investigated whether the branch for PL was long enough to be transferred to the posterior interosseous nerve (PIN). The branch diameter for PL corresponds to $46 \%$ of the PIN. The PL muscle branch presented great variability. The PL branch could be transferred to the PIN proximally to the Froshe arcade without tension in all specimens even with full range of motion of the forearm. In 13 limbs was possible the tensionless transfer to PIN distal to the branches of the supinator muscle.

KEY WORDS: Peripheral nerve injury; Nerve transfer; Median nerve; Anatomic variation.

\section{INTRODUCTION}

Nerve transfer in brachial plexus injuries is a well established procedure to restore primordial functions: for example, transfer of the musculocutaneous nerve to the biceps brachialis for restore elbow flexion (Oberlin et al., 1994), and transfer of the accessory nerve to the suprascapular nerve to restore abduction of the shoulder (Chuang, 1995).

Injuries to the radial nerve in the lower third of the arm or proximal forearm generally can be directly repaired or reconstructed with nerve grafts with good functional results (Sukegawa et al., 2016). Outcomes in surgical repair of the radial nerve are usually better than median and ulnar nerves due to its majority of motor fibers and not innervating intrinsic muscles of the hand (Lowe et al., 2002; Ray \& Mackinnon, 2011; Sukegawa et al.).

However, high radial nerve injuries, close to the axilla or posterior fascicle injury of the brachial plexus, are especially problematic. Because of the distance from target muscles and time necessary for reinnervation of extensor muscles in the forearm, these lesions usually generate functional impairments (Lowe et al.; Ray \& Mackinnon; Sukegawa et al.).

Nerve injuries are managed by direct repair, nerve grafts, tendon transfers and free functioning muscle transfers. However, some nerve injuries are not amenable to primary repair and nerve grafts does not provide satisfactory results. This includes proximal nerve lesions, extended zone of injury with large gap between stumps, and idiopathic paralysis or neuritis with no healthy nerve fibers proximally (Ustün et al., 2001; Lowe et al.; Ray \& Mackinnon; Sukegawa et al.).

In brachial plexus injuries with extended gap between stumps, there may be not sufficient time for regenerating axons to reach the target muscle motor plate before they

\footnotetext{
${ }^{1}$ Department of Surgery, Faculdade de Ciências Médicas e da Saúde, Pontifícia Universidade Católica de São Paulo (PUC-SP) - Sorocaba (SP), Brazil. ${ }^{2}$ Serviço de Cirurgia da Mão, Conjunto Hospitalar de Sorocaba (CHS), Sorocaba (SP), Brazil.

${ }^{3}$ Residence in Orthopedics, Faculdade de Ciências Médicas e da Saúde, Pontifícia Universidade Católica de São Paulo (PUC-SP) - Sorocaba (SP), Brazil.
} 
become permanently resistant to reinnervation. This prolonged period of denervation makes the target muscles susceptible to irreversible degeneration and fibrosis to the terminal motor plates (Ustün et al. ; Lowe et al.; Ray \& Mackinnon; Sukegawa et al.).

Due to the proximity of median nerve to the radial nerve branches in the elbow it has been used for restoring radial nerve function. Nerve transfers to restore wrist and fingers extension has been reported using donors such as median nerve branches to the pronator teres (PT), flexor carpi radialis (FCR), palmaris longus (PL), and flexor digitorum superficalis (FDS); anterior interosseous nerve (AIN) branches to the pronator quadratus (PQ), and radial nerve branches to the supinator (Sukegawa et al.; Ray \& Mackinnon; Ukrit et al., 2009; Bertelli \& Ghizoni, 2010; Lowe et al.; Ustün et al.). Good functional outcomes have been reported from clinical series of nerve transfers to the posterior interosseous nerve (PIN) following high radial nerve palsies and brachial plexus injuries (Nath \& Mackinnon, 2000; Sukegawa et al.; Ray \& Mackinnon; Bertelli \& Ghizoni; Ukrit et al.; Lowe et al.; Ustün et al.; García-López et al., 2014).

The aim of this study was to analyze the characteristics and anatomical variations of the PL muscle innervation and evaluate the feasibility of transferring the PL branch to restore fingers extension regarding tension in the repair and distance to target muscles.

\section{MATERIAL AND METHOD}

Thirty upper limbs of 15 male adult cadavers were prepared by intra-arterial injection of $10 \%$ glycerin and formaldehyde solution. Each forearm was dissected with full elbow extension, wrist in neutral and forearm in pronation. No specimen had evidence of previous deformity, surgical procedures or traumatic injuries in the studied area. Skin and fascia of the distal third of the arm, forearm and wrist was removed. The median nerve was identified in the arm and dissected from proximal to distal. Biceps aponeurosis was sectioned and the PT humeral head was detached distally and retracted. FCR and PL tendons were severed in their distal third to increase exposure of their motor branches. Median nerve branches to the PT, FCR, PL, FDS and AIN branches to the FDP, FPL and PQ were dissected after longitudinal division of the FDS and its fibrous arch. Anatomical variations of the PL innervation were recorded.

The radial nerve was identified in the arm between the brachialis and brachioradialis muscles. Motor branches to the brachialis (MB), brachioradialis (BR), extensor carpi radialis longus (ECRL), extensor carpi radialis brevis (ECRB); superficial branch of the radial nerve; PIN and its branches to the supinator were identified. Vascular structures were not preserved to facilitate nerve dissection. The following measures with ruler and digital pachymeter were performed: (1) forearm length measured from the center of a line between the medial and lateral epicondyles (intercondylar line) to the center of a line between the radial and ulnar styloid processes; (2) distance between the medial epicondyle and the site of PL branch origin; (3) length of the PL motor branch. In vitro evaluation of in vivo feasibility of transferring the PL branch of the PIN without tension was performed.

All the specimens made available followed the institutional ethical precepts and the project was approved by the Research Ethics Committee of the institution.

\section{RESULTS}

The median forearm length was $26.2( \pm 2.7 \mathrm{~cm})$. The mean origin of the AIN from the median nerve was $3.7 \mathrm{~cm}$ $(1.2 \pm 5.5)$ distal to the intercondylar line. The PL muscle received exclusive innervation of the median nerve in all limbs. In most it was the second muscle of the forearm to be innervated by the median and (Fig. 1A). The PL muscle was absent in 5 limbs (Fig. 1B). In five limbs we identified a branch without sharingbranches to other muscles (Fig. 1A). In four limbs it shared origin with the PT muscle (Fig. 2A), in eight with the FCR (Fig. 2B), in 2 with FDS, in 4 shared branches for PT and FCR and in two with PTM, FCR, FDS. The mean length was $(4.0 \pm 1.4)$ and the thickness measured at the midpoint of its length was $(1.4 \pm 0.6)$. The mean PIN length was $5.2 \mathrm{~mm} \pm 2.5$ and mean diameter was $3.0 \mathrm{~mm} \pm$ 0.5 . The length of the PIN was measured from its origin in the radial nerve to the distal margin of the supinator muscle. We evaluated the possibility of the median nerve branch assigned to the PL, to be transferred to the tension-free PIN, relating to the movements of forearm pronation-supination and flexion-extension of the elbow. The mean nerve diameter for the PL muscle corresponds to $46 \%$ of the PIN diameter

\section{DISCUSSION}

Anatomical treatises generally describe the most classical pattern of medial nerve distribution in the forearm: two branches (upper and lower) for PTM, a common trunk for the FCR and PL muscles, and a branch for FDS (Paturet, 

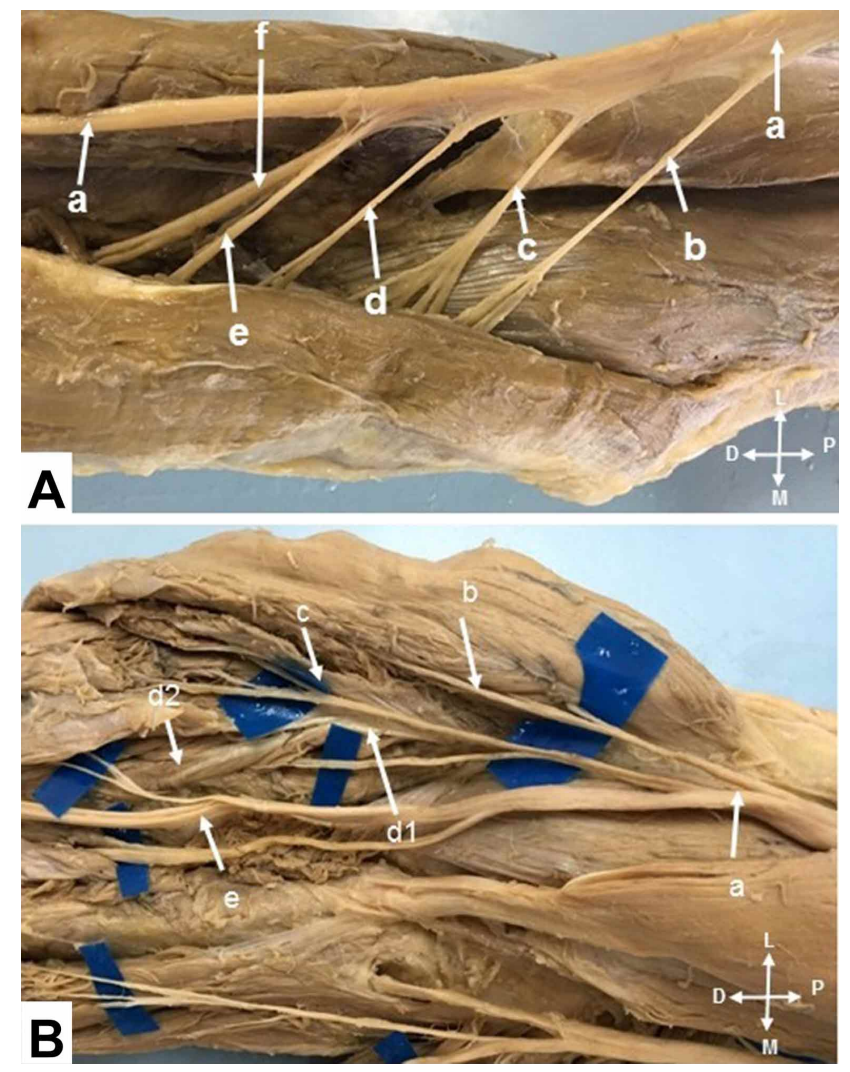

Fig. 1A. (a) median nerve; (b) branch to the pronator teres muscle; (c) branch to the palmaris longus muscle; (d) branch to the flexor carpi radialis muscle (e) branch to the flexor digitorum superficialis; (f) anterior interosseous nerve. 1B. (a) median nerve; (b) branch for the pronator teres muscle; (c) branch to the flexor carpi radialis; (d1) first branch to the flexor digitorum superficialis; (d2) second branch to the flexor digitorum superficialis; (f) anterior interosseous nerve; palmaris longus muscle absent.

1954; Rouvière \& Delmas, 1984). However, more recent studies report that there is great variability in the origin and distribution of the median nerve branches in the forearm. There is no definitive description of this innervation. Sunderland \& Ray (1946) made a biometric description of the branches, but did not distinguish the main branches of small secondary branches, does not mention the palmaris longus muscle innervation.

Canovas et al. (1998) demonstrated 10 limbs, found considerable variability in the branches for the innervated muscles by the median nerve, without a clear innervation pattern, presenting a huge variation between the branches for PT, FCR, PL and FDS muscles. It describes that in 10 dissected limbs, the branch for PL, originated as an isolated branch, without sharing branches with branches to other muscles in only one case, in nine of a fairly variable common trunk, with branches to other muscles.
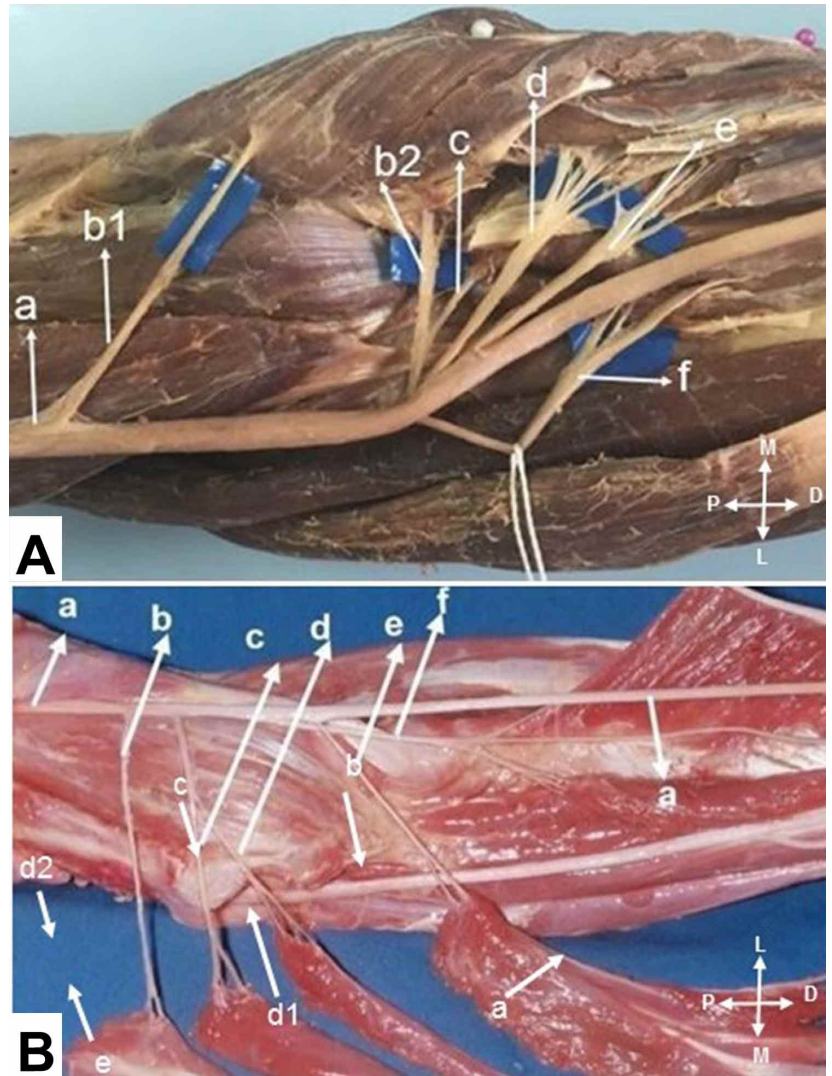

Fig. 2A. (a) median nerve; (b1) first branch to the pronator teres muscle. (Common trunk for (b2) second branch to the pronator teres muscle and (c) branch to the palmaris longus muscle). (d) branch to the flexor carpi radialis muscle (e) branch to the flexor digitorum superficialis; (f) anterior interosseous nerve. 2B. (a) median nerve; (b) branch to the pronator teres muscle. (Common trunk for (c) branch to the palmaris longus muscle and (d) branch to the flexor carpi radialis). (e) branch to the flexor digitorum superficialis; (f) anterior interosseous nerve.

Chantelot et al. (1999) studied 50 limbs, confirmed the great variability of the distribution of the branches, in only 15 limbs the PL branch did not share with branches for other muscles. They found the classic distribution (a common trunk for the FCR and PL) in only $40 \%$ of the cases.

Ukrit et al. identified an isolated limb for the PL muscle in 5 limbs, in 4 originated from a common trunk with the proximal branch of the FDS. El Zawawy et al. (2016) report that they dissected 20 forearms, identified great variability in the innervation of the forearm muscles innervated by the median, forming different nerve trunks, which were distributed to the muscles of the forearm. The PL is one of the most variable muscles in the human body (Table I) (Machado \& DiDio, 1967; Kleinert et al., 1991; Dowdy et al., 1994; Ceyhan \& Mavt, 1997; Thompson et al., 2001; O'Sullivan \& Mitchell, 2002; Ukrit et al.; Gangata, 2009; Raouf et al., 2013; El Zawawy et al.). 


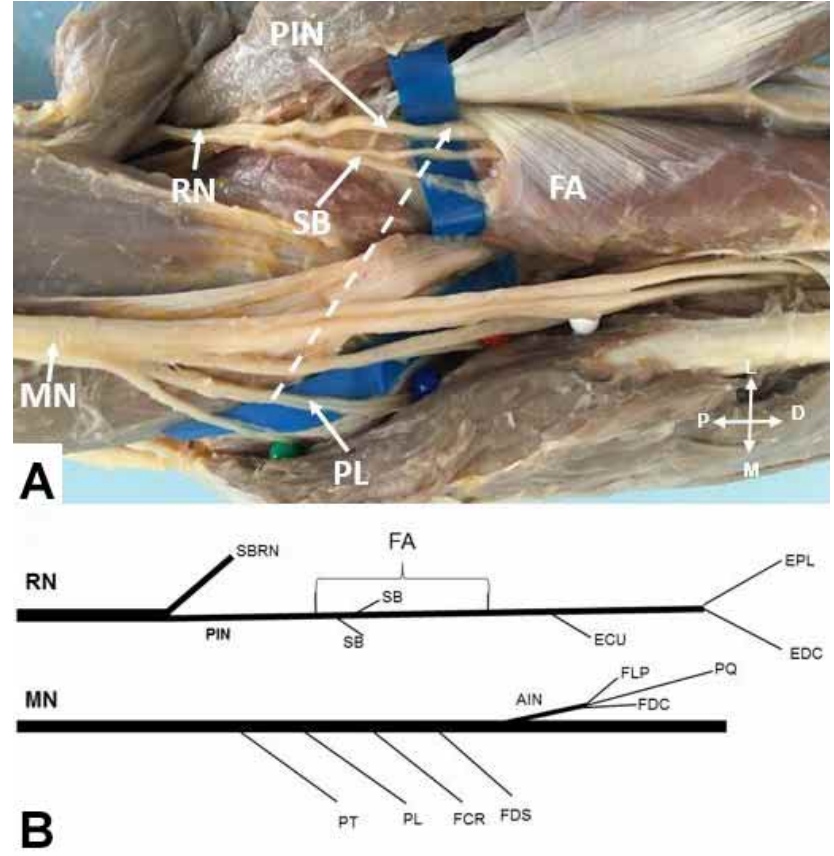

Fig. 3A. The arrow indicate the transfer of palmaris longus nerve branch (a) to posterior interosseous nerve (b) proximal to branches to supinator muscle origin (c) supinator muscle (d). B- Schematic representation of the branches of the radial and median nerves.
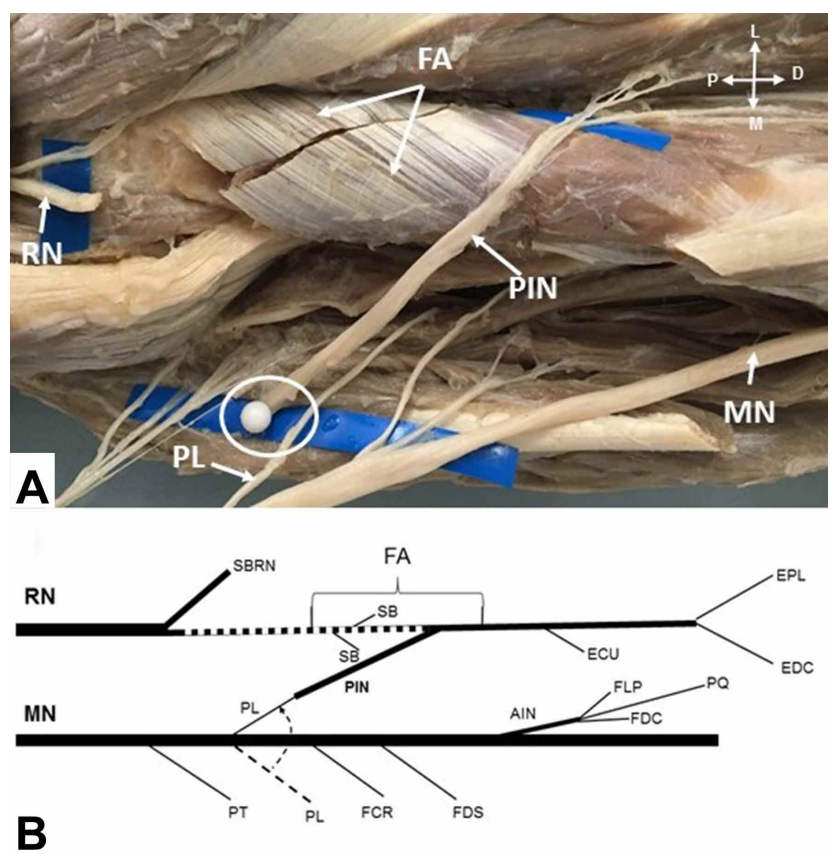

Fig. 5A. The branches to the supinator muscle were sectioned to allow the posterior interosseous nerve (a) to be moved medially shortening the distance allowing the conection with Palmaris longus branch (c). B-Schematic representation of this transfer.
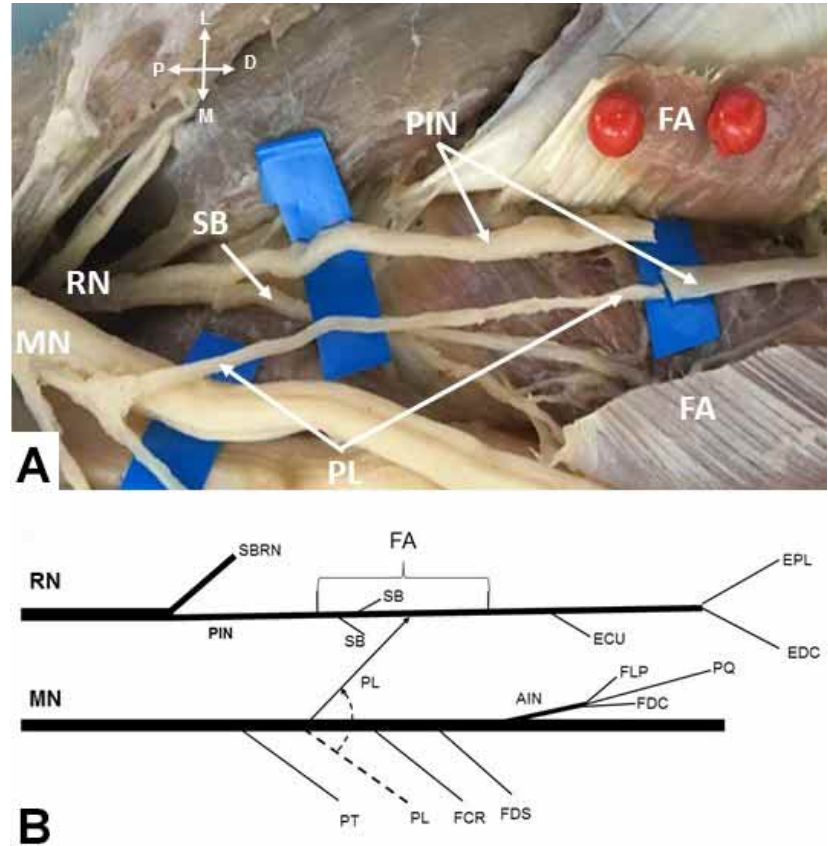

Fig. 4A. The posterior interosseous nerve (a) was sectioned distally from the origin of the branches to the supinator (b) and connected to the branch of the palmaris longus (c). The supinator muscle (d) was sectioned in the trajectory of the posterior interosseous nerve B- Schematic representation of the transfer of the palmaris distal branch to the posterior interosseous nerve.

Moore et al. (2014) report that for the restoration of radial nerve function prefer double transfer: 1 - a branch for FDS to the ECRB branch to extend the wrist. 2-The FCR or PL or both for the PIN to extend the fingers and thumb. Lowe et al. reported 2 cases of PL nerve transfer to PIN in radial nerve palsy with good results. Ukrit et al. report that in only one in 10 dissected limbs the PL muscle was absent, however the branch for PL muscle was identified in only 5 (50\%), so the branch for the PL was not constant, they consider that the average proportion of nerve fibers was not high enough compared to other branches of the median nerve. In the present anatomical study, we adopted the following procedure (Sukegawa et al.), so the branch for the PL muscle was sectioned at the neuromuscular junction and directed laterally to be connected to the PIN, its section depends on each situation and must be decided during the surgical procedure.

In 12 limbs, we noticed that the branch of the PL muscle was long enough to reach the PIN, distal to the branches to the supinator muscle, free of tension even with the movements of the forearm and elbow (Figs. 3A,B and $4 \mathrm{~A}, \mathrm{~B})$. With the advantage that donor nerve axons were not wasted in the unnecessary innervation of the supinator 
CAETANO, E. B.; VIEIRA, L. A.; FERREIRA, C. M. B.; CAVALHEIRO, C. S.; ARCURI, M. H. \& SILVA JÚNIOR, L. C. N. Anatomical study of the branch of the palmaris longus muscle for its transfer to the posterior interosseous nerve. Int. J. Morphol., 37(2):626-631, 2019.

Table I. Prevalence of absence of palmaris longus in diferent studies.

\begin{tabular}{|c|c|c|c|c|}
\hline Authors & Year & Limbs & Type of study & PL absent \\
\hline El Zawawi et al. & 2016 & 20 & Anatomical & $(60 \%)$ \\
\hline Dowdy et al. & 1994 & 52 & Anatomical & $(6 \%)$ \\
\hline O'Sullivan \& Mitchell & 2002 & 47 & Anatomical & $25(58.19 \%)$ \\
\hline Ukrit et al. & 2009 & 10 & Anatomical & $(10 \%)$ \\
\hline Kleinert et al. & 1991 & -- & Clinical (surgery) & $(15 \%)$ \\
\hline Ceyan \& Mavt (Turkish population) & 1997 & 7000 & Clinical & $4480 \quad(64 \%)$ \\
\hline Gangata (Zimbabue population) & 2009 & 890 & Clinical & $(15 \%)$ \\
\hline Machado \& Didio (Indian from Amazonia) & 1967 & 379 & Clinical & $(3.7 \%)$ \\
\hline Raouf et al. (Egyptian students) & 2013 & 386 & Clinical & $196(50.80 \%)$ \\
\hline Thompson et al. (Northern Ireland) & 2001 & 300 & Clinical & $(25 \%)$ \\
\hline Caetano et al. (in this study) & 2018 & 30 & Anatomical & $(12 \%)$ \\
\hline
\end{tabular}

muscle, because its anatomical characteristics are not used for tendinous transfers and supination is maintained by the biceps brachialis. In 13 limbs, the branch destined to the PL could be connected to the PIN, distally to the branches to the supinator muscle even with full range of motion of the forearm. In 12 limbs the branches to the supinator muscle (usually two or more branches) were sectioned to allow the PIN to be moved medially shortening the distance allowing this neurotization distal to the supinator branches. The supinator muscle was sectioned longitudinally, following the PIN path from the Froshe arcade to the distal margin of the supinator, in this way the PIN was released and can be mobilized medially towards the PL branch and can be connected without tension. This mobilization is facilitated by the section of the branches intended for the supinator, which tend to retain the PIN by restricting its excursion towards the median nerve. The section of the branches to the supinator also allows all the axons of the PIN to be directed to muscle groups that provide extension of the wrist and fingers avoiding the loss of critical axons in redundant functions. The PL muscle is sectioned as long as possible and neurolyzed as much as possible without damaging its axons, in order to favor axonal regeneration, it is desirable to perform nerve conection, as close as possible to the target muscle, without tension in the suture, even during elbow and forearm movements. This procedure was done, thus imitating in cadaver limbs the clinical procedure in vivo (Fig. $5 \mathrm{~A}, \mathrm{~B})$.

We identified that the mean diameter of the branch for the PL muscle registered in 14 limbs was $1.4 \pm 0.6$, corresponds to $46 \%$ of the diameter of the PIN $3.0 \pm 0.5$ in 30 limbs.

Several papers described in the literature, show that nerve transfers of branches with considerable diameter differences and nerve fibers provide good results. De Medinaceli et al. (1994) believe that reinnervation of 20 to
$30 \%$ of muscle fibers is compatible with normal muscle function. Jiang et al. (2007) report that axons in the proximal stump can multiply by increasing their number by 3 to 4 times. Lutz et al. (2000) demonstrated in rabbits that this axonal multiplication between donor and recipient was 1:3. Tötösy de Zepetnek et al. (1992) observed that at least $30 \%$ of the original motor neurons are needed to achieve normal muscle strength in rats. Therefore, the donor nerve must have at least $30 \%$ of the number of axons of the receptor nerve. Other factors reinforce the justification for this nerve transfer, even if the mean diameter of the PL muscle branch is $46 \%$ of the mean diameter of the PIN, for example the muscular strength necessary for the extension of the fingers and thumb is minimal, since we require little force to open the hand, the muscular force required for apprehension is greater than necessary for release (Ukrit et al.).

The median nerve branch for the PL muscle is expendable, its fibers are motor in nature, have sufficient length to be connected to the target muscles distal to the branches of the supinator, thus very close to the target muscles, diameter of $46 \%$, compatible with the diameter of the PIN according to the above studies (Tötösy de Zepetnek et al.; De Medinaceli; Jiang et al., Lutz et al.). It has the disadvantage of being absent in 5 of the $30(17 \%)$ of dissected limbs.

\section{CONCLUSION}

The PL muscle presented great variability. In 12 limbs, the branch destined to the PL could be connected to the PIN, distally to the branches to the supinator muscle even with full range of motion of the forearm. In 13 limbs it was necessary to mobilize the PIN for this neurotization. The PL branch has the potential to be transferred to the PIN, thus allowing the extension of the fingers and thumb. 
CAETANO, E. B.; VIEIRA, L. A.; FERREIRA, C. M. B.; CAVALHEIRO, C. S.; ARCURI, M. H. \& SILVA JÚNIOR, L. C. N. Estudio anatómico del ramo del músculo palmar largo para su transferencia al nervio interóseo posterior. Int. J. Morphol., 37(2):626-631, 2019 .

RESUMEN: El objetivo de este estudio fue evaluar las características anatómicas y las variaciones del ramo del músculo palmar largo y definir la posibilidad de transferir este ramo al nervio interóseo posterior sin tensión. Se disecaron 30 miembros superiores de 15 cadáveres de hombres adultos después de su preparación con $20 \%$ de glicerina y formaldehído, inyectados por vía intraarterial. En todos los miembros el músculo palmar largo (PL) recibió inervación exclusiva del nervio mediano. En la mayoría de los casos, fue el segundo músculo del antebrazo inervado por el nervio mediano. En 5 miembros estaba ausente el músculo. En 5 miembros identificamos un ramo sin compartir ramos con otros músculos. En 4 miembros, compartió el origen con el músculo pronador redondo (PR), en 8 con el músculo flexor radial del carpo (FRC), en 2 con el músculo flexor superficial de los dedos (FCSD), en 4 ramos compartidos para el PR y FRC y en dos con PR, FRC, FCSD. La longitud media fue $(4,0 \pm 1,2 \mathrm{~cm})$ y el grosor $(1,4 \pm 0,6 \mathrm{~cm})$. Investigamos si el ramo del PL era lo suficientemente largo para ser transferido al nervio interóseo posterior (NIP). El diámetro del ramo para el PL corresponde al $46 \%$ del NIP. El ramo del músculo PL presentó una gran variabilidad. El ramo del PL podría transferirse al NIP proximalmente a la «arcada de Frohse», sin tensión, en todas las muestras, incluso con el rango completo de movimiento del antebrazo. En 13 miembros fue posible la transferencia sin tensión al NIP distal a los ramos del músculo supinador.

PALABRAS CLAVE: Traumatismos; Nervios periféricos; Transferencia de nervios; Nervio mediano; Variación anatómica.

\section{REFERENCES}

Bertelli, J. A. \& Ghizoni, M. F. Transfer of supinator motor branches to the posterior interosseous nerve in C7-T1 brachial plexus palsy. J. Neurosurg., 113(1):129-32, 2010

Canovas, F.; Mouilleron, P. \& Bonnel, F. Biometry of the muscular branches of the median nerve to the forearm. Clin. Anat., 11(4):239-45, 1998.

Ceyhan, O. \& Mavt, A. Distribution of agenesis of palmaris longus muscle in 12 to 18 years old age groups. Indian J. Med. Sci., 51(5):156-60, 1997.

Chantelot, C.; Feugas, C.; Guillem, P.; Chapnikoff, D.; Rémy, F. \& Fontaine, C. Innervation of the medial epicondylar muscles: an anatomic study in 50 cases. Surg. Radiol. Anat., 21(3):165-8, 1999.

Chuang, D. C. Neurotization procedures for brachial plexus injuries. Hand Clin., 11(4):633-45, 1995.

De Medinaceli, L. (Ed.). Cell Surgery to Repair Divided Nerves. New York, CASIS-CID, 1994. pp.90-101.

Dowdy, P. A.; Richards, R. S. \& McFarlane, R. M. The palmar cutaneous branch of the median nerve and the palmaris longus tendon: a cadaveric study. $J$. Hand Surg. Am., 19(2):199-202, 1994.

El Zawawy, E. M.; El Sekily, N. M.; Fouad, W. A.; Emam, M. H. \& Hassan, M. M. Median nerve motor entry points in the forearm - clinical application. Eur. J. Anat., 20(1):1-17, 2016.

Gangata, $\mathrm{H}$. The clinical surface anatomy anomalies of the palmaris longus muscle in the Black African population of Zimbabwe and a proposed new testing technique. Clin. Anat., 22(2):230-5, 2009.

García-López, A.; Navarro, R.; Martinez, F. \& Rojas, A. Nerve transfers from branches to the flexor carpi radialis and pronator teres to reconstruct the radial nerve. J. Hand Surg. Am., 39(1):50-6, 2014.
Jiang, B. G.; Yin, X. F.; Zhang, D. Y.; Fu, Z. G. \& Zhang, H. B. Maximum number of collaterals developed by one axon during peripheral nerve regeneration and the influence of that number on reinnervation effects. Eur Neurol., 58(1):12-20, 2007.

Kleinert, H. E.; Pulvertaft, R. G. \& Smith, D. J. Flexor Tendon Grafting in the Hand. In: Jupiter, J. B. (Ed.). Flynn's Hand Surgery. Baltimore, Williams \& Wilkins, 1991. pp.285.

Lowe, J. B. 3rd.; Tung, T. R. \& Mackinnon, S. E. New surgical option for radial nerve paralysis. Plast. Reconstr. Surg., 110(3):836-43, 2002.

Lutz, B. S.; Chuang, D. C.; Chuang, S. S.; Hsu, J. C.; Ma, S. F. \& Wei, F. C. Nerve transfer to the median nerve using parts of the ulnar and radial nerves in the rabbit--effects on motor recovery of the median nerve and donor nerve morbidity. J. Hand Surg. Br., 25(4):329-35, 2000.

Machado, A. B. \& DiDio, L. J. Frequency of the musculus palmaris longus studied in vivo in some Amazon indians. Am. J. Phys. Anthropol., 27(1):1120, 1967.

Moore, A. M.; Franco, M. \& Tung, T. H. Motor and sensory nerve transfers in the forearm and hand. Plast. Reconstr. Surg., 134(4):721-30, 2014.

Nath, R. K. \& Mackinnon, S. E. Nerve transfers in the upper extremity. Hand Clin., 16(1):131-9, 2000

O'Sullivan, E. \& Mitchell, B. S. Association of the absence of palmaris longus tendon with an anomalous superficial palmar arch in the human hand. $J$. Anat., 201(5):405-8, 2002.

Oberlin, C.; Béal, D.; Leechavengvongs, S.; Salon, A.; Dauge, M. C. \& Sarcy, J. J. Nerve transfer to biceps muscle using a part of ulnar nerve for C5-C6 avulsion of the brachial plexus: anatomical study and report of four cases. $J$. Hand Surg. Am., 19(2):232-7, 1994.

Paturet, G. Traité d'Anatomie Humaine. Tome 2. Paris, Masson, 1954. pp.472-7.

Raouf, H. A.; Kader, G. A.; Jaradat, A.; Dharap, A.; Fadel, R. \& Salem, A. H. Frequency of palmaris longus absence and its association with other anatomical variations in the Egyptian population. Clin. Anat., 26(5):572-7, 2013.

Ray, W. Z. \& Mackinnon, S. E. Clinical outcomes following median to radial nerve transfers. J. Hand Surg. Am., 36(2):201-8, 2011.

Rouvière, H. \& Delmas, A. Anatomie Humaine. Tome 3. Paris, Masson, 1984. pp.232-3.

Sukegawa, K.; Suzuki, T.; Ogawa, Y.; Kobayashi, T.; Matsuura, Y. \& Kuniyoshi, $\mathrm{K}$. A cadaver study of median-to-radial nerve transfer for radial nerve injuries. J. Hand Surg. Am., 41(1):20-6, 2016.

Sunderland, S. \& Ray, L. J. Metrical and non-metrical features of the muscular branches of the median nerve. J. Comp. Neurol., 85(2):191-203, 1946.

Thompson, N. W.; Mockford, B. J. \& Cran, G. W. Absence of the palmaris longus muscle: a population study. Ulster Med. J., 70(1):22-4, 2001.

Tötösy de Zepetnek, J. E.; Zung, H. V.; Erdebil, S. \& Gordon, T. Innervation ratio is an important determinant of force in normal and reinnervated rat tibialis anterior muscles. J. Neurophysiol., 67(5):1385-403, 1992.

Ukrit, A.; Leechavengvongs, S.; Malungpaishrope, K.; Uerpairojkit, C.; Chongthammakun, S. \& Witoonchart, K. Nerve transfer for wrist extension using nerve to flexor digitorum superficialis in cervical 5, 6, and 7 root avulsions: anatomic study and report of two cases. J. Hand Surg. Am., 34(9):1659-66, 2009.

Ustün, M. E.; Ogün, T. C. \& Büyükmumcu, M. Neurotization as an alternative for restoring finger and wrist extension. J. Neurosurg., 94(5):795-8, 2001.

\section{Corresponding author:}

Prof. Dr. Edie Benedito Caetano

Pontifícia Universidade Católica de São Paulo

Faculdade de Ciências Médicas e da Saúde

Rua Joubert Wey, 290

CEP: $18030-070$ Sorocaba

São Paulo-BRASIL

Email: ediecaetano@uol.com.br

Received: 24-10-2018

Accepted: 07-01-2019 